\title{
Incidence, risk factors and outcome of acute kidney injury (AKI) in patients with COVID-19
}

\author{
Gaetano Alfano ${ }^{1,2}\left(\right.$ D Annachiara Ferrari ${ }^{3} \cdot$ Francesco Fontana $^{1} \cdot$ Giacomo Mori ${ }^{1} \cdot$ Riccardo Magistroni $^{1,3}$. \\ Marianna Meschiari ${ }^{4}$. Erica Franceschini ${ }^{4}$. Marianna Menozzi ${ }^{4}$. Gianluca Cuomo ${ }^{4}$. Gabriella Orlando ${ }^{4}$. \\ Antonella Santoro ${ }^{4} \cdot$ Margherita Digaetano $^{4}$ - Cinzia Puzzolante ${ }^{4} \cdot$ Federica Carli $^{4} \cdot$ Andrea Bedini $^{4} \cdot$ Jovana Milic $^{2,3}$. \\ Irene Coloretti ${ }^{5}$. Paolo Raggi ${ }^{6}$. Cristina Mussini ${ }^{3,4}$. Massimo Girardis ${ }^{5}$. Gianni Cappelli ${ }^{1,3}$. Giovanni Guaraldi ${ }^{3,4}$. for \\ the Modena Covid-19 Working Group (MoCo19)
}

Received: 7 December 2020 / Accepted: 7 June 2021 / Published online: 1 July 2021

(c) Japanese Society of Nephrology 2021

\begin{abstract}
Background Acute kidney injury (AKI) is a severe complication of coronavirus disease-2019 (COVID-19). This study aims to evaluate incidence, risk factors and case-fatality rate of AKI in patients with COVID-19.

Methods We reviewed the health medical records of 307 consecutive patients with COVID-19 hospitalized at the University Hospital of Modena, Italy.

Results AKI was diagnosed in 69 out of 307 (22.4\%) COVID-19 patients. Stages 1, 2, or 3 AKI accounted for 57.9\%, 24.6\% and $17.3 \%$, respectively. AKI patients had a mean age of $74.7 \pm 9.9$ years. These patients showed higher serum levels of the main markers of inflammation and higher rate of severe pneumonia than non-AKI patients. Kidney injury was associated with a higher rate of urinary abnormalities including proteinuria $(0.44 \pm 0.85 \mathrm{vs} 0.18 \pm 0.29 \mathrm{mg} / \mathrm{mg} ; P=<0.0001)$ and microscopic hematuria $(P=0.032)$ compared to non-AKI patients. Hemodialysis was performed in $7.2 \%$ of the subjects and $33.3 \%$ of the survivors did not recover kidney function after AKI. Risk factors for kidney injury were age, male sex, CKD and higher non-renal SOFA score. Patients with AKI had a mortality rate of 56.5\%. Adjusted Cox regression analysis revealed that COVID-19-associated AKI was independently associated with in-hospital death (hazard ratio $[\mathrm{HR}]=4.82 ; \mathrm{CI}$ 95\%, 1.36-17.08) compared to non-AKI patients.

Conclusion AKI was a common and harmful consequence of COVID-19. It manifested with urinary abnormalities (proteinuria, microscopic hematuria) and conferred an increased risk for death. Given the well-known short-term sequelae of AKI, prevention of kidney injury is imperative in this vulnerable cohort of patients.
\end{abstract}

Keywords COVID-19 $\cdot$ AKI $\cdot$ Dialysis $\cdot$ Mortality $\cdot$ Urine $\cdot$ Risk factors

Gaetano Alfano

gaetano.alfano@unimore.it

1 Nephrology Dialysis and Transplant Unit, University Hospital of Modena, Modena, Italy

2 Clinical and Experimental Medicine PhD Program, University of Modena and Reggio Emilia, Modena, Italy

3 Surgical, Medical and Dental Department of Morphological Sciences, Section of Nephrology, University of Modena and Reggio Emilia, Modena, Italy

4 Department of Infectious Diseases, University Hospital of Modena, Modena, Italy

5 Department of Anesthesia and Intensive Care Unit, University Hospital of Modena, Modena, Italy

6 Department of Medicine, Division of Cardiology, Mazankowski Alberta Heart Institute, Alberta, Canada

\section{Introduction}

COVID-19 is a complex infectious disease characterized by a broad spectrum of manifestations ranging from asymptomatic to severe illness [1]. The disease is associated with a high rate of morbidity and mortality in patients hospitalized for severe symptoms of SARS-CoV-2 pneumonia [2]. Lung is the main target of the virus, but other organs including brain, liver and kidneys can be involved in this infection [3]. The pathogenesis of COVID-19 is poorly understood and the principal etiology of organ dysfunction seems due to the direct and indirect effects of proinflammatory cytokines release [4-6]. 
The rate of acute kidney injury (AKI) in COVID-19 is unclear, but recent evidence has established that kidney involvement is proportional to the severity of the underlying lung involvement [7]. Studies conducted in China and the US reported a high prevalence of urinary abnormalities (proteinuria and microscopic hematuria) and a rate of AKI ranging from $0.5 \%$ to $36.6 \%$ [7-13]. A report from Bordeaux (France) documented that the impact of AKI has been estimated to about $80 \%$ in severely ill patients admitted in ICU [14].

The etiological mechanism leading to kidney injury is still unknown. Direct cytopathologic damage, cytokine storm/sepsis, drug toxicity and dehydration may be potential interlinked mechanisms of kidney injury in COVID-19 patients. A great number of living and post-mortem kidney biopsies showed a widespread proximal tubule injury consistent with acute tubular necrosis [15-17]. Collapsing glomerulopathy and thrombotic microangiopathy were other common findings on kidney biopsy [16, 18]. The use of offending agents including nonsteroidal anti-inflammatory drugs [19] and high-dose vitamin C [20] has been associated with kidney involvement. Lastly, the detection of the virus in renal parenchyma and consequently in urine leads to hypothesize a potential cytopathic effect of the virus [21], though the pathogenetic mechanism of SARS-CoV-2driven kidney injury remains elusive. Based on these data, understanding the impact of SARS-CoV-2 infection on kidney function is necessary to elucidate epidemiological and clinical characteristics of patients experiencing AKI. The aim of this study was to evaluate the incidence, risk factors and outcome of AKI in COVID-19 patients.

\section{Methods}

\section{Study design and setting}

This retrospective, observational study was conducted in patients with laboratory confirmed-COVID-19 admitted to the University Hospital of Modena. The city of Modena is geographically located in Emilia Romagna region that overall accounted for a total amount of 28.143 documented COVID-19 cases on June 18, 2020 [22]. Clinical and laboratory data were prospectively recorded in consecutively admitted patients from 23 February to 27 April 2020. This time frame coincided with the observational period of the study.

The study was approved by the regional ethical committee of Emilia Romagna (prot. n. 0013376/20).

\section{Population}

This study recruited all consecutive adult patients ( $\geq 18$ years) admitted with SARS-CoV-2 infection. Patients with chronic kidney disease (CKD) in renal replacement therapy were excluded from the analysis. According to the WHO guidelines, the diagnosis of SARS-CoV-2 infection was defined as a positive real-time reverse transcriptase-polymerase chain reaction (RT-PCR) assay of nasopharyngeal swabs or lower respiratory tract specimens. [23].

\section{Standard of care}

Delivery of healthcare services for all SARS-CoV-2 infected patients was ensured by a public healthcare system. Care of COVID-19 patients was delivered by an integrated multidisciplinary team including infectious disease specialists, pneumologists, internal medicine physicians, nephrologists, rheumatologists, intensive care and coagulation specialists. Patients were admitted on general and infectious disease ward.

According to the Italian Society of Infectious Diseases' Guidelines (SIMIT) [24] and recent data on the treatment of COVID-19 [25, 26], all patients received standard of care treatment including:

(a) oxygen supply to achieve a target oxygen saturation $\left(\mathrm{SO}_{2}\right) \geq 90 \%$; (b) hydroxychloroquine (400 $\mathrm{mg}$ BID on day 1 followed by $200 \mathrm{mg}$ BID on days 2 to 5); (c) azithromycin (500 mg QD for 5 days); (d) darunavir/cobicistat (800/150 mg QD) for 14 days; (e) low-molecular weight heparin for prophylaxis of deep vein thrombosis.

From 18 March 2020, combined therapy darunavir/ cobicistat was stopped due to the supervening information on the lack of clinical benefit of protease inhibitors (e.g., lopinavir) to treat COVID-19 [27]. A sub-cohort of patients received tocilizumab treatment in addition to the standard of care when they met the following criteria: $\mathrm{SO}_{2}<92 \%$ and $\mathrm{PaO}_{2} / \mathrm{FiO}_{2}<200 \mathrm{mmHg}$ in room air or a decrease in $\mathrm{PaO}_{2} / \mathrm{FiO}_{2}>30 \%$ in the previous $24 \mathrm{~h}$ after hospitalization.

Severely ill patients were evaluated by intensive care consultants for ICU admission and invasive mechanical ventilation eligibility. Medical history, age, comorbidities, vital signs, physical and laboratory examinations were assessed daily.

\section{Criteria and definition}

AKI was defined according to the 2012 Kidney Disease: Improving Global Outcomes (KDIGO) criteria [28]. Three AKI stages were classified as follows: 
(i) stage 1: increase in serum creatinine ( $\mathrm{sCr}) \geq 0.3 \mathrm{mg} /$ $\mathrm{dl}$ within $48 \mathrm{~h}$ or 1.5-1.9 times increase of baseline $\mathrm{sCr}$ measured within 7 days; (ii) stage 2: 2-2.9 times increase of baseline sCr measured within 7 days; (iii) stage 3: 3 times or greater increase in baseline $\mathrm{sCr}$ measured within 7 days or $\mathrm{sCr} \geq 4 \mathrm{mg} / \mathrm{dl}$ within $48 \mathrm{~h}$ or the initiation of renal replacement therapy [28]. Stage of AKI was the highest stage reached during hospitalization. Urine output criteria was not used for the diagnosis of AKI.

Baseline $\mathrm{sCr}$ was defined as the last available sCr measurement within 365 days before the onset of COVID-19 symptoms. When not available prior to the diagnosis of COVID-19, sCr measured on admission was used as the 'baseline' value.

The estimated glomerular filtration rate (eGFR) was calculated using the Chronic Kidney Disease Epidemiology Collaboration (CKD-EPI) equation [29].

Polypharmacy occured when five or more medications were used [30].

Non-renal SOFA score was calculated by subtracting the score resulting from the degree of renal dysfunction from total score [31].

Requirements for admission to the ICU were: (i) hypoxia despite noninvasive ventilatory support; (ii) hemodynamic instability; (iii) cardiac arrest; (iv) respiratory arrest; (v) multiorgan failure.

\section{Data collection}

Data collected from electronic medical records included demographics, comorbidities, medications, laboratory values, vital signs and outcomes. They were prospectively recorded from hospital admission. Comorbidities were identified upon review of the patient's medical records. International Classification of Diseases (ICD) was used to code and classify mortality data from death certificates.

\section{Outcome}

The primary outcome measure was the incidence of AKI in hospitalized patients with COVID-19. Additional analyses included the detection of risk factors for AKI and its relationship with mortality.

\section{Statistical analysis}

Baseline characteristics were analyzed using descriptive statistics and were reported as proportions, mean (standard deviation [SD]) or median (interquartile range [IQR]) as appropriate. $\chi 2$ test or Fisher's test was used to analyze categorical variables. Analyses of continuous variables were compared using an unpaired t-test or Kruskal-Wallis test, as appropriate. ANOVA has been used to evaluate the differences between AKI stages. A gamma distribution function was used to plot the probability of AKI events during hospitalization.

Mortality and incidence of AKI were evaluated using Kaplan-Meier (K-M) curves. Univariate and multivariate analysis were performed by Cox regression to identify risk factors for AKI. Cox regression also assessed the association between AKI and in-hospital mortality, after adjusting for sex, age, CKD, cardiovascular disease (CVD), diabetes, non-renal SOFA score and chronic obstructive pulmonary disease (COPD).

A $P$ value of less than 0.05 was considered statistically significant. SPSS $23 \circledR$ was used for statistical analysis.

\section{Results}

\section{Clinical characteristics of patients with AKI}

A total of 307 patients were included in the study. During the study period, 22.4\% $(n=69)$ of patients developed AKI. The mean age of patients with AKI was $74.7 \pm 9.9$ years. $\mathrm{sCr}$ was measured 734 times in the AKI group (10.6 times per patient) during the average period of hospitalization lasting $16.7 \pm 10.6$ days.

Mean baseline sCr in the AKI group was $1.08 \pm 0.5 \mathrm{mg} /$ $\mathrm{dl}$, peaking $2.6 \pm 1.8 \mathrm{mg} / \mathrm{dl}$ after $9.3 \pm 7.9$ days from admission. Patients with AKI reported a higher level of proteinuria $(0.44 \pm 0.85$ vs $0.18 \pm 0.29 \mathrm{mg} / \mathrm{mg} ; P \leq .0001)$ and hematuria $(P=0.032)$ compared to patients without AKI. The main markers of organ involvement (BNP, troponin, AST, INR) and systemic inflammatory response (IL-6, C-reactive protein [CRP], ferritin) were significantly higher than non-AKI group (Tables 1 and 2).

The rate of mechanical ventilation and ICU admission in AKI group was $26 \%$ and $34.7 \%$, respectively. Overall, patients with severe acute respiratory distress syndrome requiring mechanical ventilation had a higher rate of AKI events than non-mechanically ventilated patients $(P=0.045)$. In particular, the incidence of AKI stage 2 and 3, and unrecovered AKI was higher in patients on mechanical ventilation (Supplementary Table 1).

\section{Stage of AKI}

Patients with AKI were stratified according to the 2012 KDIGO guidelines and were distributed as follows: stage 1: $57.9 \%$, stage $2: 24.6 \%$, and stage $3: 17.3 \%$. At the end of follow-up, $33.3 \%$ of the survivors did not have a full recovery of their kidney function as prior to admission. Five 
Table 1 Demographics and lab examinations of AKI and nonAKI patients

\begin{tabular}{|c|c|c|c|c|}
\hline Variable & $\begin{array}{l}\text { All patients* } \\
(n=307)\end{array}$ & $\begin{array}{l}\mathrm{AKI}^{*} \\
(n=69)\end{array}$ & $\begin{array}{l}\text { No-AKI* } \\
(n=238)\end{array}$ & $\begin{array}{l}\text { AKI vs. no-AKI* } \\
P \text { value }\end{array}$ \\
\hline Age, years & $65.2 \pm(14.01)$ & $74.7 \pm 9.9$ & $62.4 \pm 13.8$ & $<0.0001$ \\
\hline Range & $25-94.4$ & $43-94.2$ & $25-94.4$ & \\
\hline Males, n. (\%) & $219(71.3)$ & $55(79.7)$ & $164(68.9)$ & 0.096 \\
\hline \multicolumn{5}{|l|}{ Race/ethnicity, n. (\%) } \\
\hline White & $298(97)$ & $68(98.5)$ & $230(96.6)$ & 0.689 \\
\hline Black & $7(2.2)$ & - & $7(2.9)$ & 0.35 \\
\hline Other & $2(0.6)$ & $1(1.4)$ & $1(0.4)$ & 0.399 \\
\hline \multicolumn{5}{|l|}{ Lab test, mean $( \pm \mathrm{SD})$} \\
\hline Hemoglobin, g/l & 11,9 & $11.2 \pm 2.1$ & $12.2 \pm 1.76$ & $<0.001$ \\
\hline White cells, $\mathrm{mm}^{3}$ & $9175 \pm 3650$ & $11,454 \pm 7805$ & $8160 \pm 4304$ & 0.542 \\
\hline Platelets, $10^{9} / 1$ & $264.3 \pm 128.7$ & $231.7 \pm 122.2$ & $276.2 \pm 129$ & $<0.0001$ \\
\hline Glycemia & $106 \pm 47.8$ & $111.7 \pm 47.5$ & $104.1 \pm 47.7$ & 0.14 \\
\hline Potassium, mmol/l & $4.6 \pm 3$ & $4.01 \pm 0.6$ & $4.01 \pm 3.3$ & 0.991 \\
\hline Sodium, mmol/1 & $137.6 \pm 4$ & $139 \pm 5.52$ & $137.2 \pm 3.5$ & $<0.001$ \\
\hline Calcium, mg/l & $8.5 \pm 0.5$ & $8.4 \pm 0.578$ & $8.6 \pm 0.5$ & 0.873 \\
\hline Albumin, gr/dl & $2.9 \pm 0.5$ & $2.7 \pm 0.49$ & $3.06 \pm 0.47$ & $<0.0001$ \\
\hline Urea, mg/dl & $59 \pm 41.7$ & $87.8 \pm 55.3$ & $45.9 \pm 24.4$ & $<0.0001$ \\
\hline D-dimer, mg/l & $6064.2 \pm 7183.6$ & $5090.2 \pm 6588$ & $3130 \pm 4969$ & $<0.0001$ \\
\hline Alanine amino-transferase, $\mathrm{U} / \mathrm{l}$ & $136.7 \pm 827.1$ & $339 \pm 161$ & $67.8 \pm 78.8$ & $<0.0001$ \\
\hline Bilirubin, mg/l & $0.8 \pm 0.7$ & $0.99 \pm 1.2$ & $0.74 \pm 0.58$ & $<0.001$ \\
\hline INR & $1.15 \pm 0.4$ & $1.33 \pm 0.73$ & $1.09 \pm 0.16$ & $<0.0001$ \\
\hline Lactate dehydrogenase, $\mathrm{U} / 1$ & $960.8 \pm 3173.1$ & $1782.4 \pm 6183$ & $679.2 \pm 350.7$ & $<0.0001$ \\
\hline Ferritin $\mathrm{ng} / \mathrm{ml}$ & $944.8 \pm 684.3$ & $958.6 \pm 691.7$ & $914.3 \pm 683.3$ & 0.824 \\
\hline CPK, U/I & $211.1 \pm 687.8$ & $285.2 \pm 1071$ & $187.6 \pm 507.4$ & 0.008 \\
\hline $\mathrm{BNP}, \mathrm{pg} / \mathrm{ml}$ & $129.3 \pm 194.6$ & $221.6 \pm 273$ & $98.4 \pm 148.3$ & $<0.0001$ \\
\hline Troponin, ng/ml & $173.3 \pm 1239$ & $276.6 \pm 1775$ & $77.01 \pm 183.7$ & 0.338 \\
\hline IL-6, ng/L & $531.1 \pm 684.6$ & $784.8 \pm 888$ & $444.4 \pm 575.3$ & $<0.0001$ \\
\hline C-reactive protein, $\mathrm{mg} / \mathrm{l}$ & $6.78 \pm 7.8$ & $6.87 \pm 7.9$ & $6.74 \pm 7.8$ & 0.737 \\
\hline \multicolumn{5}{|l|}{ Kidney function } \\
\hline sCr measurements, $\mathrm{n}$. & 2542 & 734 & 1808 & \\
\hline Number of $\mathrm{sCr} / \mathrm{pt}$ & 8,2 & 10,6 & 7,6 & \\
\hline Baseline $\mathrm{sCr}, \mathrm{mg} / \mathrm{dl}$ & $0.97 \pm 0.58$ & $1.08 \pm 0.5$ & $0.8 \pm 0.2$ & $<0.0001$ \\
\hline Range & $0.24-3.78$ & $0.46-3.78$ & $0.24-2.19$ & \\
\hline eGFR, $\mathrm{ml} / \mathrm{min}$ & $83.6 \pm 22.3$ & $69.3 \pm 21.8$ & $87.75 \pm 20.8$ & $<0.0001$ \\
\hline Range & $14.8-147$ & $14.8-111.9$ & $28.5-147$ & \\
\hline Peak sCr, mg/dl & $1.3 \pm 1.1$ & $2.6 \pm 1.8$ & $0.9 \pm 0.2$ & $<0.0001$ \\
\hline Nadir sCr, mg/dl & $0.7 \pm 0.5$ & $1.1 \pm 0.8$ & $0.6 \pm 0.2$ & $<0.0001$ \\
\hline Urine protein-to-creatinine ratio, $\mathrm{mg} / \mathrm{mg}$ & $0.27 \pm 0.57$ & $0.44 \pm 0.88$ & $0.18 \pm 0.29$ & $<0.0001$ \\
\hline Spot urine $\mathrm{Na}^{+}, \mathrm{Eq} / \mathrm{L}$ & $97.93 \pm 58,48$ & $75.11 \pm 40.69$ & $80.27 \pm 39.64$ & 0.763 \\
\hline Spot urine $\mathrm{K}^{+}, \mathrm{Eq} / \mathrm{L}$ & $36.97 \pm 20.57$ & $40 \pm 15.04$ & $42.24 \pm 27.52$ & 0.813 \\
\hline \multicolumn{5}{|l|}{ Microscopic hematuria, n. (\%) } \\
\hline Absent & $99(32.2)$ & $12(26.6)$ & $87(36.5)$ & 0.032 \\
\hline$\pm /+$ & $31(10)$ & $19(42.2)$ & $22(16)$ & $<0.0001$ \\
\hline++ & $14(4.5)$ & $4(8.8)$ & $10(7.2)$ & 0.525 \\
\hline+++ & $11(3.5)$ & $2(4.4)$ & $9(6.5)$ & 0.098 \\
\hline++++ & $17(5.5)$ & $8(17.7)$ & $9(6.5)$ & 0.03 \\
\hline
\end{tabular}

Statistically significant $p$ values are in bold

$A K I$ acute kidney injury, BNP Brain Natriuretic Peptide, $C K D$ chronic kidney disease, $C P K$ creatine phosphokinase, $e G F R$ estimated glomerular filtration rate, $I L-6$ interleukin-6, INR international normalized ratio, $s \mathrm{Cr}$ serum creatinine

*Results are expressed as mean \pm standard deviation (SD) unless differently indicated 
patients with AKI stage III progressed to dialysis (chronic venous-venous hemodialysis [CVVH] or hemodialysis [HD]) in the intensive care unit (ICU); all five died as a consequence of multiorgan failure (MOF). The main differences between AKI stages are detailed in Supplementary Table 2. Data showed that AKI stage 3 patients had a higher baseline value of CRP and SOFA score and a more severe respiratory distress $\left[\mathrm{PaO}_{2} / \mathrm{FiO}_{2}, 90(66-15)\right]$ compared to patients with AKI stage 1 and 2. No pre-existent differences in terms of morbidities were observed between these two groups of patients.

As shown in Fig. 1, the cumulative incidence curves show a steep rise in AKI stage 3 events within the first 10-15 days from admission.

Observation of the frequency histogram (Fig. 2) and the probability distribution plot (Fig. 3) revealed a peak of AKI events at the timing of hospital admission that decreased gradually up to the end of the follow-up period. A substantial clustering of AKI events was noted before patients' exitus (Fig. 3B).

\section{Risk factors for AKI}

To capture probable causes of AKI (e.g., dehydration, hypotension), patients with kidney injury were subdivided into smaller groups, but analysis of the main lab test examinations, performed at baseline and at diagnosis of kidney injury, did not reveal any clinically significant differences. (Supplementary Table 3).

Univariable Cox regression analysis revealed that age $(\mathrm{HR}=1.064 ; 95 \% \mathrm{CI}, 1.04-1.08), \mathrm{CKD}(\mathrm{HR}=2.88 ; 95 \% \mathrm{CI}$, 1.76-4.71) and non-renal sequential organ failure assessment (SOFA) score ( $>3$ points) $(\mathrm{HR}=2.05 ; 95 \%$ CI $1.27-3.30)$ were statistically significant predictors of AKI. Age over 65 years $(\mathrm{HR}=4.24 ; 95 \% \mathrm{CI} 2.23-8.09)$ and $\mathrm{GFR}<45 \mathrm{ml} /$ $\min (\mathrm{HR}=2.28$; CI\% 1.31-3.97) were the strongest predictors of kidney injury.

Multivariable analyses showed that non-renal SOFA score ( $>3$ points) $(\mathrm{HR}=1.91 ; 95 \% \mathrm{CI}, 1.17-3.11)$, age $(\mathrm{HR}=1.05 ; 95 \% \mathrm{CI}, 1.03-1.08), \mathrm{CKD}(\mathrm{HR}=2.03$; 95\% CI, 1.17-3.51) and male sex $(\mathrm{HR}=2.62 ; 95 \% \mathrm{CI}$, 1.41-4.84) were independent risk factors for AKI in our cohort of patients (Table 3 ).

\section{Outcome}

Patients with AKI had an overall mortality rate of $56.5 \%$. A high mortality rate was detected in patients with AKI stage $2(82.4 \%)$ and $3(83.3 \%)$. The primary causes of death were respiratory failure $(61.5 \%)$, followed by sepsis (15.3\%) and septic shock with MOF (9\%). Crude mortality was significantly higher in AKI patients (56\% vs $6.7 \%$;
$P \leq 0.0001)$ compared to patients with normal kidney function (Table 2).

K-M curves showed high mortality for all patients with AKI, including AKI stage 1 (log-rank $p<0.0001)$ (Fig. 4).

Patients experiencing AKI had an unadjusted HR for death of 7.18 (95\% CI, 4.01-12.86).

In a multivariable $\mathrm{COX}$ regression analysis that included age, sex, comorbidities (diabetes mellitus, CVD, CKD, COPD and non-renal SOFA, the HR for in-hospital death in patients with AKI was 4.82 (95\% CI, 1.36-17.08) and 13.21 (95\% CI, 2.92-59.69) in patients with unrecovered kidney function at the end of the follow-up compared to non-AKI (Table 4).

\section{Discussion}

The results of this study confirm the recently published data reporting AKI as a frequent event in COVID-19. In a cohort of 307 patients hospitalized for severe respiratory symptoms due to SARS-CoV-2 infection, AKI complicated the clinical course of $69(22.4 \%)$ patients. In the majority of them (57.9\%) AKI was mild (stage 1), whereas AKI stage 2 and 3 accounted for $24.6 \%$ and $17.3 \%$ of the cases, respectively. As already noted in previous studies, [7, 13] kidney injury was accompanied by a higher burden of urinary abnormalities such as microscopic hematuria and proteinuria compared to patients who did not experience AKI. Renal function was replaced in $7.2 \%$ of patients with AKI by continuous renal replacement therapy. The outcome of these patients was poor because all died of refractory septic shock evolving in multiorgan failure. Of note, one-third of survivors did not have complete renal recovery at the end of follow-up.

AKI is a devastating syndrome with a significant impact on morbidity and mortality [32]. Early reports from Chinese cohorts documented a low prevalence of renal involvement $[8,33]$. Subsequent observational studies conducted in larger cohorts reported an incidence of AKI ranging from $0.5 \%$ to $10.4 \%$ [8-13]. A recent study evaluating 5449 patients in the New York metropolitan area confirmed that AKI was a frequent complication of COVID-19 [7] since it was diagnosed in more than onethird of patients. AKI occurred in patients with a high burden of comorbidities and, mainly in patients with respiratory distress requiring mechanical ventilation. We are unable to explain the wide variability in the prevalence of AKI, but different criteria adopted for the definition of AKI, population selection, $\mathrm{sCr}$ measurement frequency and timing of hospital admission are all potential determinants of these heterogeneous estimates. In our study, AKI was predominantly diagnosed in symptomatic older patients (74.7 versus 62.4 years) experiencing a more 
Table 2 Clinical characteristics and outcome of AKI and non-AKI patients

\begin{tabular}{|c|c|c|c|c|}
\hline Variable & $\begin{array}{l}\text { All patients* } \\
(n=307)\end{array}$ & $\begin{array}{l}\mathrm{AKI} * \\
(n=69)\end{array}$ & $\begin{array}{l}\text { Non-AKI* } \\
(n=238)\end{array}$ & $\begin{array}{l}\text { AKI vs. non-AKI* } \\
P \text { value }\end{array}$ \\
\hline Mean arterial pressure $(\mathrm{mmHg})$ & $65.5 \pm 9$ & $67.5 \pm 9.1$ & $65.0 \pm 8.9$ & 0.109 \\
\hline $\mathrm{PO}_{2} / \mathrm{FiO}_{2}$ & $236.11 \pm 114$ & $150.4 \pm 82.6$ & $250.7 \pm 85.2$ & $<0.0001$ \\
\hline SOFA score & $2.6 \pm 1.5$ & $3.8 \pm 1.8$ & $2.31 \pm 1.2$ & $<0.0001$ \\
\hline Range & $0-9$ & $0-9$ & $0-8$ & \\
\hline Comorbidities, n. (\%) & $189(61.8)$ & $44(63.7)$ & $145(60.9)$ & 0.778 \\
\hline COPD & $32(10)$ & $10(14.4)$ & $18(7.6)$ & 0.095 \\
\hline Diabetes & $54(17.6)$ & $15(21.7)$ & $39(16.4)$ & 0.001 \\
\hline Hypertension & $138(45)$ & $34(49.2)$ & $104(43.7)$ & 0.414 \\
\hline $\mathrm{CVD}^{\#}$ & $70(22.8)$ & $23(33.3)$ & $47(19.7)$ & 0.225 \\
\hline Obesity & $28(30.8)$ & $8(11.5)$ & $20(8.4)$ & 0.475 \\
\hline CKD (GFR <60 ml/min), n. (\%) & $51(16.6)$ & $26(37.6)$ & $25(10.5)$ & $<0.0001$ \\
\hline CKD Stage $3 \mathrm{a}$ & $33(10.7)$ & $17(24.6)$ & $16(6.7)$ & $<0.0001$ \\
\hline CKD Stage $3 b$ & $13(4.2)$ & $6(8.6)$ & $7(2.9)$ & 0.018 \\
\hline CKD Stage 4 & $4(1.3)$ & $2(2.9)$ & $2(0.8)$ & $<0.0001$ \\
\hline CKD Stage 5 & $1(0.3)$ & $1(1.4)$ & - & 0.224 \\
\hline Polypharmacy (> 5 drugs), n. (\%) & $175(57)$ & $44(63.7)$ & $131(55)$ & 0.215 \\
\hline Diuretic agent, n. (\%) & $46(14.9)$ & $26(37.6)$ & $20(8.4)$ & $<0.0001$ \\
\hline Tocilizumab, n. (\%) & $152(49.5)$ & $33(47.8)$ & $111(46.6)$ & 0.891 \\
\hline \multicolumn{5}{|l|}{ Nephrotoxic agents, n. (\%) } \\
\hline NSAID & $10(3.3)$ & $3(4.3)$ & $7(2.9)$ & 0.699 \\
\hline RAS-blocker & $32(10.4)$ & $5(7.2)$ & $27(11.3)$ & 0.38 \\
\hline Nephrotoxic antibiotics & $17(5.5)$ & $7(10.1)$ & $10(4.2)$ & 0.722 \\
\hline Darunavir/cobicistat & $123(40)$ & $24(34.7)$ & $99(41.5)$ & 0.337 \\
\hline Time from symptoms to admission, days & $8 \pm 6.65$ & $6.36 \pm 5.7$ & $8.51 \pm 6.79$ & 0.0461 \\
\hline Time from admission to mechanical ventilation, days & $2.11 \pm 2.05$ & $2.25 \pm 2$ & $2.12 \pm 2.24$ & 0.978 \\
\hline Time from admission to AKI, days & $5.8 \pm 6.3$ & $9.3 \pm 7.9$ & $4.6 \pm 7.2$ & $<0.0001$ \\
\hline Time from admission to death, days & $12.3 \pm 7.2$ & $11.8 \pm 7.3$ & $13.4 \pm 7$ & 0.45 \\
\hline ICU admission, n. (\%) & $61(19.8)$ & $24(34.7)$ & $37(15.5)$ & $<0.001$ \\
\hline Mechanical ventilation, n. (\%) & $53(17.2)$ & $18(26)$ & $35(14.7)$ & 0.045 \\
\hline \multicolumn{5}{|l|}{ AKI, $n .(\%)$} \\
\hline AKI Stage 1 & $40(13)$ & $40(57.9)$ & - & \\
\hline AKI Stage 2 & $17(5.5)$ & $17(24.6)$ & - & \\
\hline AKI Stage 3 & $12(3.9)$ & $12(17.3)$ & - & \\
\hline Not recovered AKI in survivors, $n .(\%)$ & $10(3.9)$ & $45(33.3)$ & - & \\
\hline Renal replacement therapy, n. (\%) & $5(1.6)$ & $5(7.2)$ & - & \\
\hline Hospital length of stay, days & $14.8 \pm 9.7$ & $16.7 \pm 10.6$ & $14.3 \pm 9.3$ & 0.07 \\
\hline Range & $0-46$ & $1.9-45.8$ & $0.8-46$ & \\
\hline Currently hospitalized, n. (\%) & $71(23.12)$ & $18(26.08)$ & $53(22.26)$ & 0.519 \\
\hline Hospital mortality, n. (\%) & $55(17.9)$ & $39(56.5)$ & $16(6.7)$ & $<0.0001$ \\
\hline \multicolumn{5}{|l|}{ Cause of death, n. (\%) } \\
\hline ARDS & $33(10.7)$ & $24(61.5)$ & $9(56.2)$ & 0.767 \\
\hline Sepsis & $10(3.2)$ & $6(15.3)$ & $4(25)$ & 0.453 \\
\hline Septic shock & $12(3.9)$ & $9(23)$ & $3(18.7)$ & 1 \\
\hline
\end{tabular}

Statistically significant $p$ values are in bold

$A R D S$ acute respiratory distress syndrome, COPD chronic obstructive pulmonary disease, CVD cardiovascular disease, NSAID nonsteroidal antiinflammatory drug, $R A S$ renin-angiotensin system, ICU intensive care unit, SOFA sequential organ failure assessment

${ }^{\#}$ Cardiovascular disease includes heart failure, ischemic heart disease and arrhythmia

*Results are expressed as mean \pm standard deviation (SD), unless differently indicated 
Fig. 1 Cumulative incidence of AKI events stratified according to KDIGO stage 1-3 during hospitalization

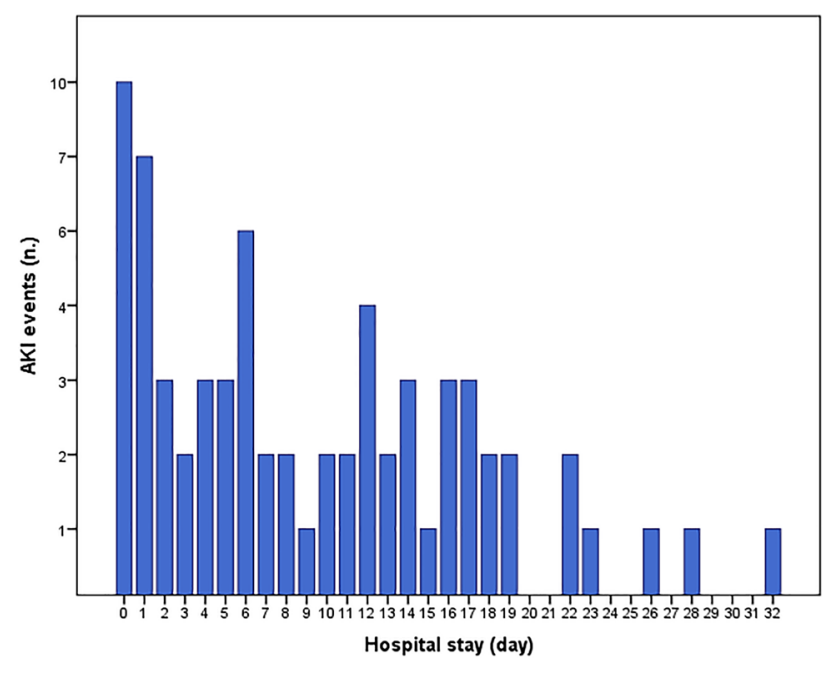

Fig. 2 Incidence of AKI events during hospitalization for COVID-19

severe infection compared to non-AKI subjects. Patients who developed AKI presented a significantly more severe systemic disease (SOFA score, 3.8 versus 2.3 ), a high level of the classical biomarkers of systemic inflammation (IL-6, LDH, D-dimer, albumin, platelet count, hemoglobin, ferritin) and impairment of other organs including lung $\left(\mathrm{PO}_{2} / \mathrm{FiO}_{2}\right)$, heart (troponin, $\left.\mathrm{BNP}\right)$ and liver (bilirubin, ALT).

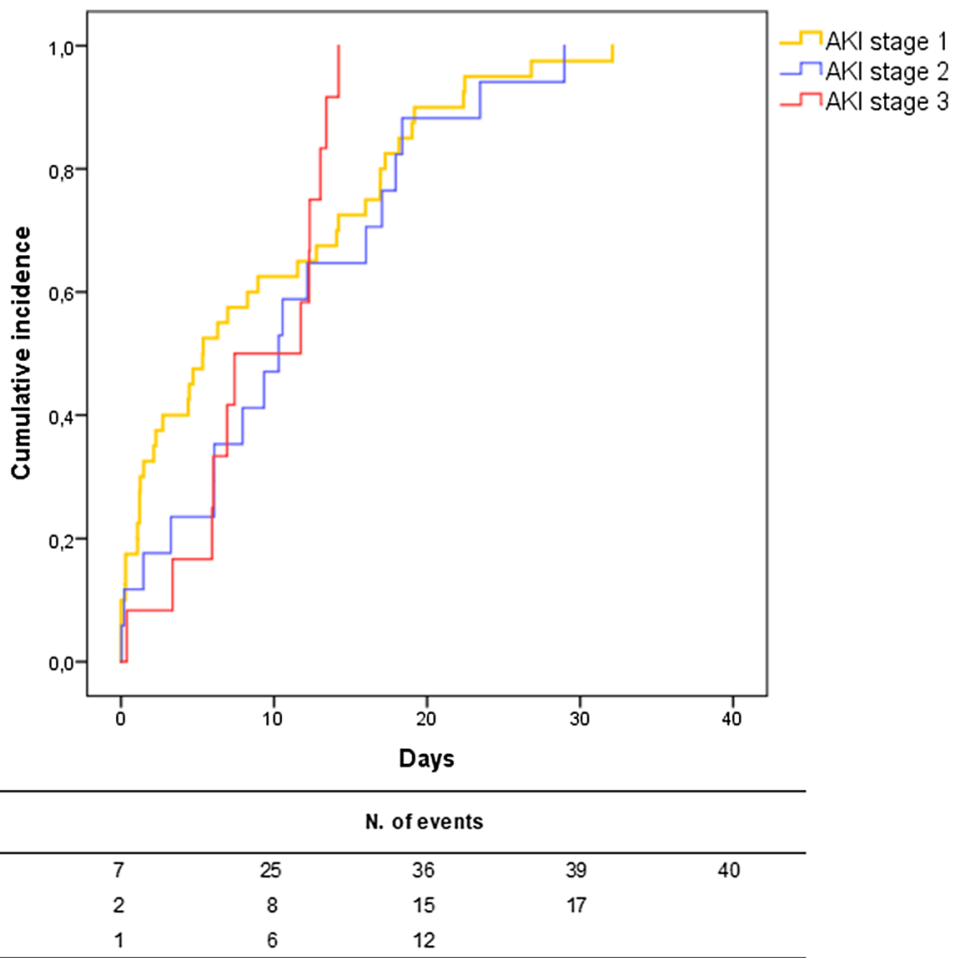

Of interest, an early peak was noted in the timeline of AKI development. Similar to the findings of Hirsch et al. [7], this high number of AKI events, coinciding with admission, imposes a careful management of COVID-19 patients within few hours from admission. Early assessment of basic vital parameters and hemodynamic stabilization of critically ill patients may reduce, as far as possible, the severity of kidney injury. After the first peak, observation of our data showed a substantial clustering of AKI events before death. In this setting, the diagnosis of AKI reflected the severity of COVID-19 that in the most severe cases manifested with multiple organs failure including AKI.

Etiology of COVID-19-associated AKI is not fully understood. Potential triggering factors include hemodynamic disturbance, inflammation and exposure to nephrotoxic agents. A further cause of AKI is kidney tropism of SARS-CoV-2. Recent studies provided insights into the ability of the virus to target the tubular and glomerular cells of the kidney, especially in critically ill patients. [34, 35]. In the present study, we have no data to prove direct virus damage of renal parenchyma. The incidence of AKI was more frequent among patients with CKD and diabetes mellitus, comorbidities largely known to be associated with an increased vulnerability to kidney injury [36-38]. Analysis of risk factors, showed that non-renal SOFA score, age, male sex and CKD were statistically significant predictors 

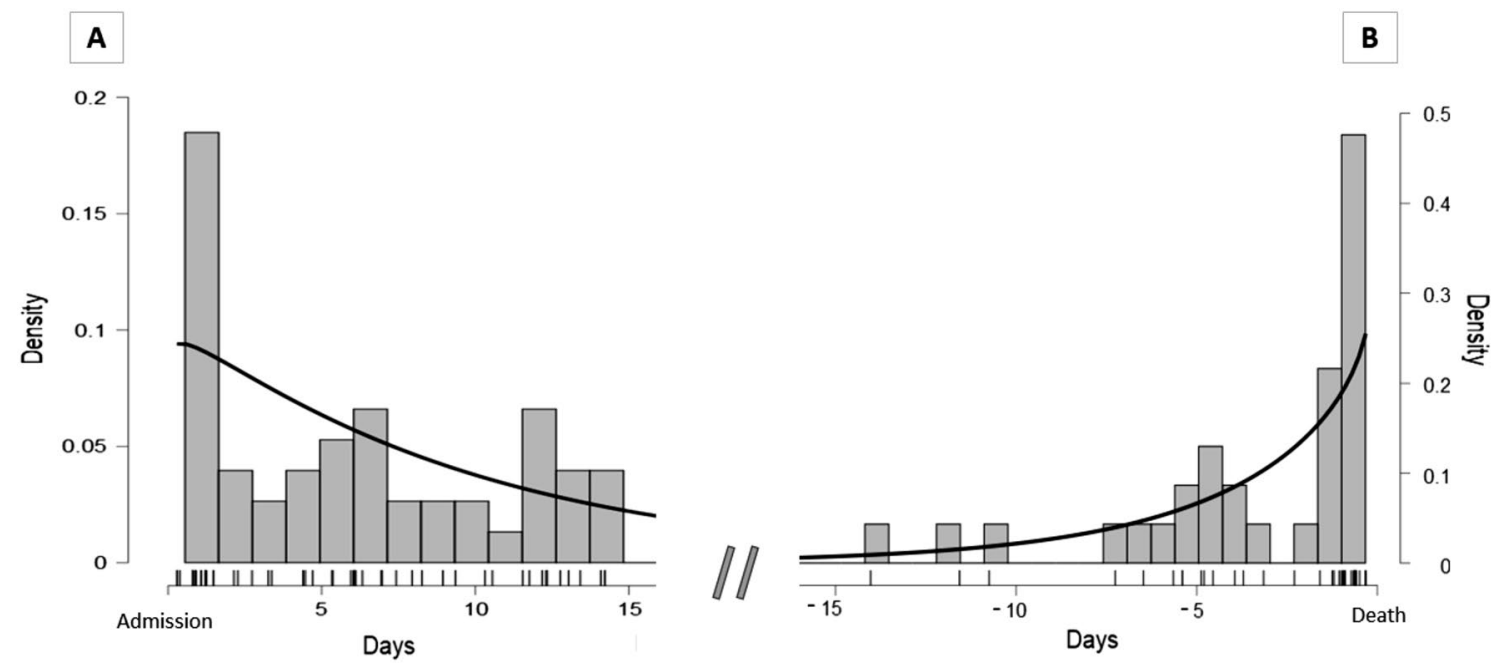

Fig. 3 Probability of AKI related to hospital admission (A) and death (B). In $\mathbf{B}$, the plot of the probability density function included only nonsurvivors

of AKI. According to our findings, age [39], male sex [40], CKD [41] are well-known risk factors for AKI in the general population. SOFA score is a reliable prognostic scoring for critically ill patients with sepsis [42] as well as kidney injury [43-46]. Furthermore, extrarenal SOFA score has been identified as independent predictors for AKI in a cohort of non-COVID-19 critically ill surgical patients. [47] In the setting of SARS-CoV-2 infection, a study conducted on 5216 US veterans provided evidence that older age, male sex and lower baseline eGFR were independent risk factors for AKI during hospitalization. [48] In parallel to our findings, several studies confirmed that age [7, $49,50]$, male gender [50, 51], severe COVID-19 (respiratory distress) [52] and CKD [49, 51] were independent risk factors for the development of COVID-19-associated AKI during hospitalization.

The identification of these risk factors may elucidate potential strategies for the prevention of kidney injury, as this event is independently associated with in-hospital mortality. The burden of this association is estimated to confer about five-fold excess risk of mortality in patients with AKI and 13-fold in subjects with unrecovered AKI. Detection of vulnerable patients at risk for AKI, prevention and supportive strategy in patients prone to AKI could improve the prognosis of these patients and prevent long-term consequences [53]. According to national health policies, we suggest implementing home assistance of infected patients to minimize the surge of critically ill patients in already overwhelmed hospitals. Therapeutical strategies providing intravenous hydration in dehydrated patients, avoidance of nephrotoxic agents (NSAIDs) and early withdrawn of offending agents (i.e., diuretics, RAS-blockers) may be beneficial if undertaken before arrival in hospital.

Several limitations of this study should be mentioned, some of which intrinsic to the retrospective nature of the study. A certain number of AKI events may be underdiagnosed because of the unavailability of urinary output and $\mathrm{sCr}$ at the time of symptoms onset. As a result, the incidence of AKI may be underestimated in our population, however, this limit also recurs in recently published retrospective studies on AKI [13, 14].

Although the hazard ratio for death has been adjusted for potential demographic and clinical confounding variables, we cannot rule out the effect of other unrecognized cofounders. We used the non-renal SOFA score to avoid collinearity between predictor and outcomes. We are confident that the adjustment of our model for this strong clinical variable reinforced the relationship between AKI and in-hospital mortality. Lastly, the lack of data on the long-term outcome of kidney injury, do not allow to weight the real consequences of AKI in term of morbidity and mortality in a cohort of patients at high risk for CKD. 


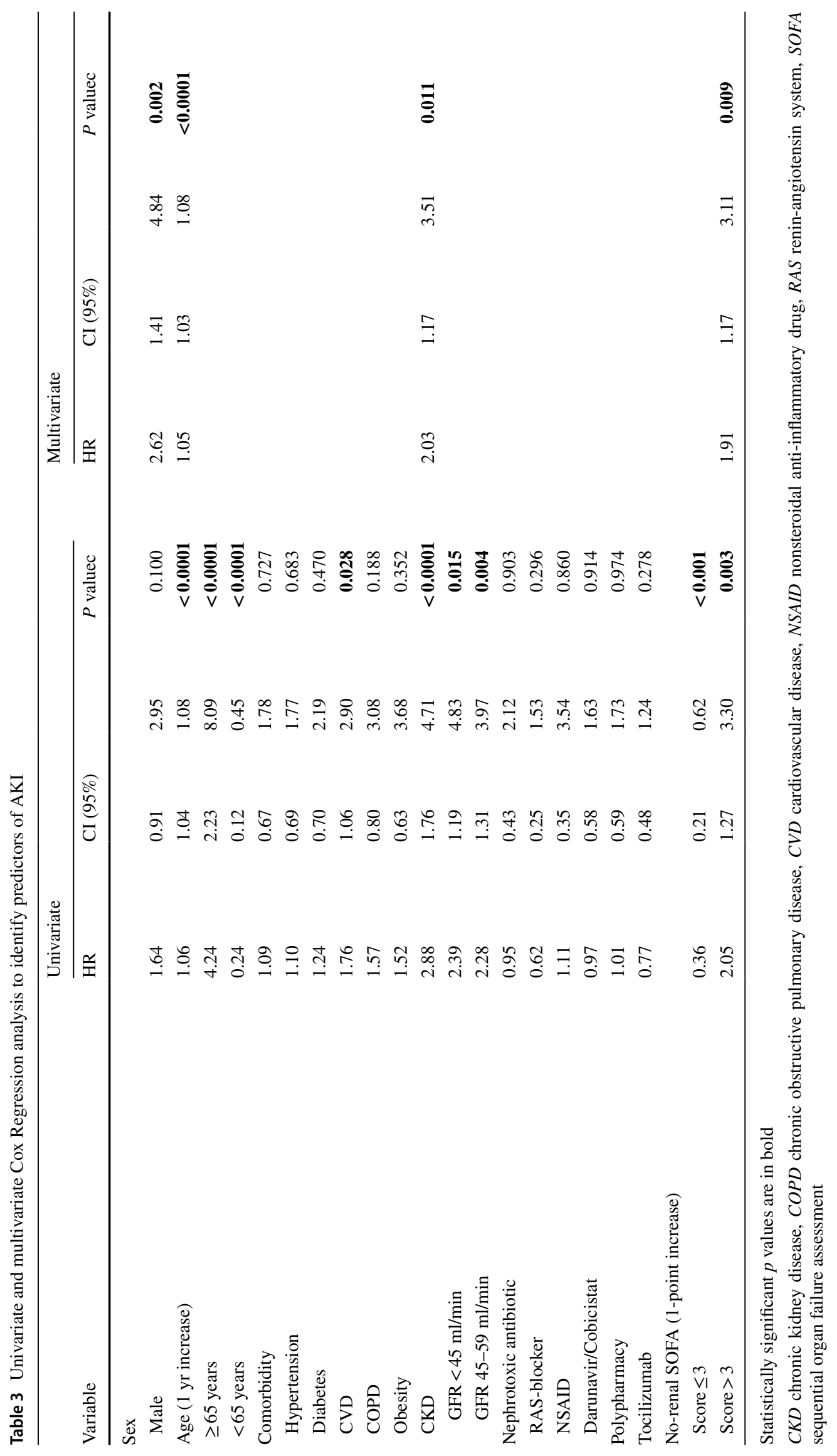


Fig. 4 Kaplan-Meyer survival analysis between patients with AKI stage 1-3 and non-AKI

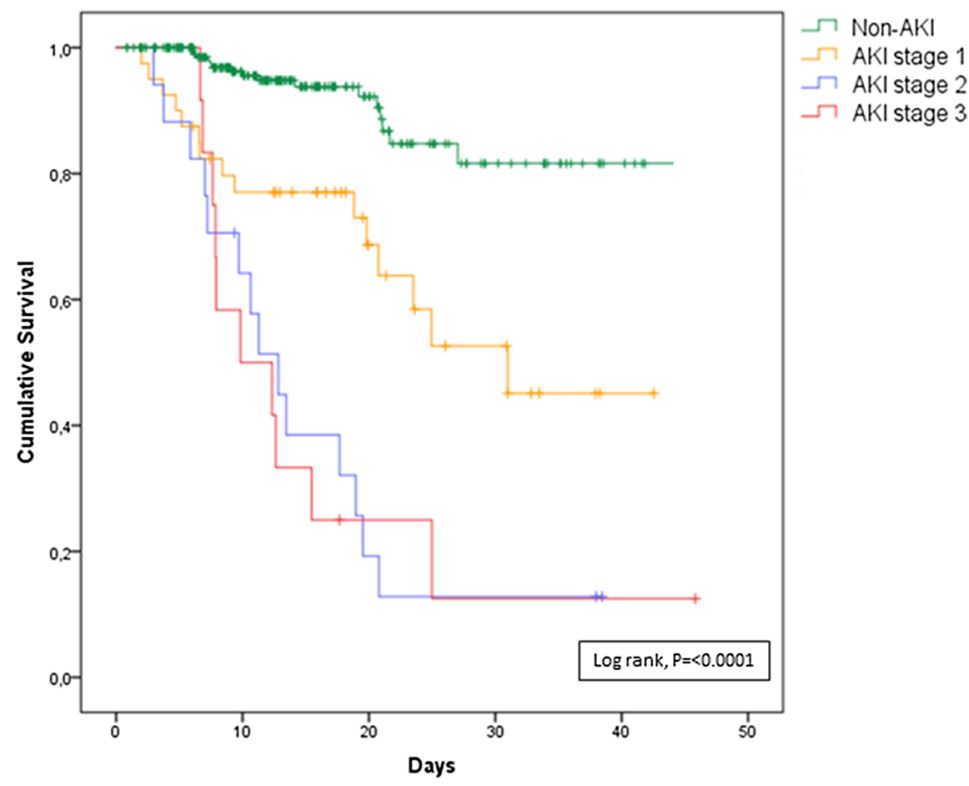

\begin{tabular}{lcrrrrrr}
\hline & N. events/pts & \multicolumn{7}{c}{ N. of pts at risk } \\
\hline Non-AKI & $16 / 238$ & 238 & 143 & 56 & 20 & 5 & 0 \\
AKI stage1 & $15 / 40$ & 40 & 29 & 14 & 8 & 1 & 0 \\
AKI stage2 & $14 / 17$ & 17 & 10 & 3 & 2 & 0 & \\
AKI stage3 & $10 / 12$ & 12 & 6 & 2 & 1 & 1 & 0 \\
\hline
\end{tabular}

Table 4 Adjusted and unadjusted Cox proportional hazard regression model for death with 95\% confidence interval in patients with AKI

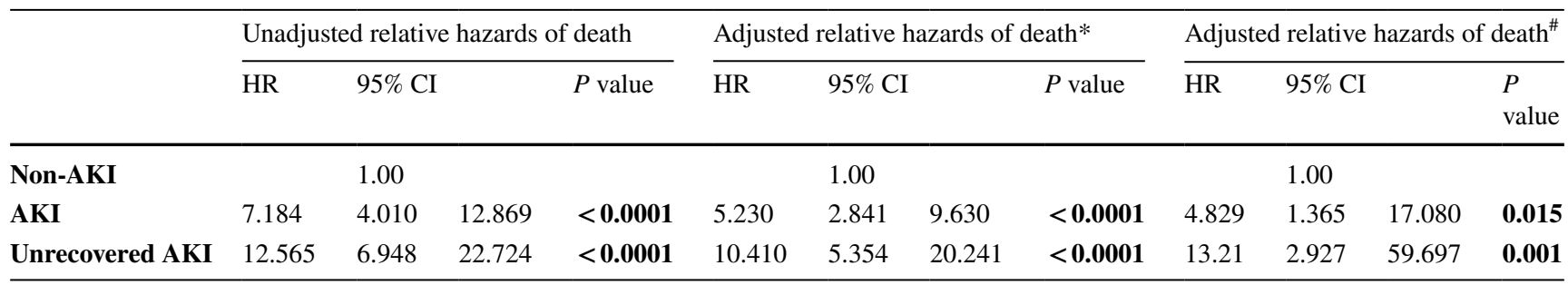

Statistically significant $p$ values are in bold

CI denotes confidential interval

*Hazard ratio adjusted for age and sex

${ }^{\#}$ Hazard ratio adjusted for age, sex, no-renal SOFA score, chronic kidney disease, cardiovascular disease, diabetes and chronic obstructive pulmonary disease

\section{Conclusion}

Acute kidney injury was a frequent complication of COVID-19. In our cohort of hospitalized patients it occured in one-fifth of the population. AKI was generally diagnosed in symptomatic elderly patients with hypoxemia and a severe systemic inflammatory response to the ongoing infection. Non-renal SOFA (score $>3$ ), age, male sex and CKD were risk factors for AKI in our cohort of patients. Identification of the etiological mechanism of AKI and strategy aimed to prioritize the prevention and early identification of AKI are urgently required, as AKI is an independent predictor of all-cause mortality in COVID-19.

Supplementary Information The online version contains supplementary material available at https://doi.org/10.1007/s10157-021-02092-x.

Acknowledgements Modena Covid-19 Working Group (MoCo19) includes:

Cristina Mussini, Giovanni Guaraldi, Erica Bacca, Andrea Bedini, Vanni Borghi, Giulia Burastero, Federica Carli, Giacomo Ciusa, Luca Corradi, Gianluca Cuomo, Margherita Digaetano, Giovanni Dolci, Matteo Faltoni, Riccardo Fantini, Giacomo Franceschi, Erica 
Franceschini, Vittorio Iadisernia, Damiano Larné, Marianna Menozzi, Marianna Meschiari, Jovana Milic, Gabriella Orlando, Francesco Pellegrino, Alessandro Raimondi, Carlotta Rogati, Antonella Santoro, Roberto Tonelli, Marco Tutone, Sara Volpi, and Dina Yaacoub (Infectious Diseases Clinics, University Hospital, via del Pozzo 71, 41124 Modena, Italy);

Gianni Cappelli, Riccardo Magistroni, Gaetano Alfano, Francesco Fontana, Ballestri Marco, Giacomo Mori (Nephrology Dialysis and Transplant Unit, University Hospital of Modena, Modena, Italy);

Massimo Girardis, Alberto Andreotti, Emanuela Biagioni, Filippo Bondi, Stefano Busani, Giovanni Chierego, Marzia Scotti, and Lucia Serio (Department of Anesthesia and Intensive Care, University Hospital, via del Pozzo 71, 41124 Modena, Italy);

Andrea Cossarizza, Caterina Bellinazzi, Rebecca Borella, Sara De Biasi, Anna De Gaetano, Lucia Fidanza, Lara Gibellini, Anna Iannone, Domenico Lo Tartaro, Marco Mattioli, Milena Nasi, Annamaria Paolini, and Marcello Pinti (Chair of Pathology and Immunology, University of Modena and Reggio Emilia, Via Campi, 287, 41125 Modena, Italy).

Funding This study was not funded.

Data availability The data underlying this article will be shared on a reasonable request to the corresponding author.

\section{Declarations}

Conflict of interest All the authors have declared no competing interest.

Ethical approval All procedures performed in studies involving human participants were in accordance with the ethical standards of the institutional and/or national research committee and with the 1964 Helsinki declaration and its later amendments or comparable ethical standards. This manuscript has been published as a preprint article on a preprint server at the following link: https://www.medrxiv.org/content/10.1101/ 2020.06.24.20138230v1 [54]. Ethics Committee of Region Emilia Romagna approved the study (n. 0013376/20).

Informed consent Written informed consent was not obtained for containment measures.

\section{References}

1. Zhu N, Zhang D, Wang W, et al. A novel coronavirus from patients with pneumonia in China, 2019. N Engl J Med. 2020. https://doi.org/10.1056/NEJMoa2001017.

2. Baud D, Qi X, Nielsen-Saines K, Musso D, Pomar L, Favre G. Real estimates of mortality following COVID-19 infection. Lancet Infect Dis. 2020. https://doi.org/10.1016/S1473-3099(20) 30195-X.

3. Zaim S, Chong JH, Sankaranarayanan V, Harky A. COVID-19 and multiorgan response. Curr Probl Cardiol. 2020. https://doi. org/10.1016/j.cpcardiol.2020.100618.

4. Cao X. COVID-19: immunopathology and its implications for therapy. Nat Rev Immunol. 2020;20(5):269-70. https://doi.org/ 10.1038/s41577-020-0308-3.

5. Alfano G, Guaraldi G, Fontana F, et al. The role of the reninangiotensin system in severe acute respiratory syndrome-CoV-2 infection. Blood Purif. 2020. https://doi.org/10.1159/000507914.

6. Cossarizza A, De Biasi S, Guaraldi G, Girardis M, Mussini C, Modena Covid-19 Working Group (MoCo19)\#. SARS-CoV-2, the virus that causes COVID-19: cytometry and the new challenge for global health. Cytom Part J Int Soc Anal Cytol. 2020;97(4):340-3. https://doi.org/10.1002/cyto.a.24002.

7. Hirsch JS, Ng JH, Ross DW, et al. Acute kidney injury in patients hospitalized with COVID-19. Kidney Int. 2020. https:// doi.org/10.1016/j.kint.2020.05.006.

8. Huang C, Wang Y, Li X, et al. Clinical features of patients infected with 2019 novel coronavirus in Wuhan China. Lancet. 2020;395(10223):497-506. https://doi.org/10.1016/S01406736(20)30183-5.

9. Chen N, Zhou M, Dong X, et al. Epidemiological and clinical characteristics of 99 cases of 2019 novel coronavirus pneumonia in Wuhan, China: a descriptive study. The Lancet. 2020;395(10223):507-13. https://doi.org/10.1016/S01406736(20)30211-7.

10. Cheng Y, Luo R, Wang K, et al. Kidney disease is associated with in-hospital death of patients with COVID-19. Kidney Int. 2020;97(5):829-38. https://doi.org/10.1016/j.kint.2020.03.005.

11. Guan W, Ni Z, Hu Y, et al. Clinical characteristics of coronavirus disease 2019 in China. N Engl J Med. 2020. https://doi.org/ 10.1056/NEJMoa2002032.

12. Wang D, Hu B, Hu C, et al. Clinical characteristics of 138 hospitalized patients with 2019 novel coronavirus-infected pneumonia in Wuhan, China. JAMA. 2020;323(11):1061. https://doi. org/10.1001/jama.2020.1585.

13. Pei G, Zhang Z, Peng J, et al. Renal involvement and early prognosis in patients with COVID-19 pneumonia. J Am Soc Nephrol. 2020. https://doi.org/10.1681/ASN.2020030276.

14. Rubin S, Orieux A, Prevel R, et al. Characterization of acute kidney injury in critically ill patients with severe coronavirus disease 2019. Clin Kidney J. 2020. https://doi.org/10.1093/ckj/sfaa099.

15. Su H, Yang M, Wan C, et al. Renal histopathological analysis of 26 postmortem findings of patients with COVID-19 in China. Kidney Int. 2020. https://doi.org/10.1016/j.kint.2020.04.003.

16. Kudose S, Batal I, Santoriello D, et al. Kidney biopsy findings in patients with COVID-19. J Am Soc Nephrol JASN. 2020;31(9):1959-68. https://doi.org/10.1681/ASN.2020060802.

17. Rossi GM, Delsante M, Pilato FP, et al. Kidney biopsy findings in a critically Ill COVID-19 patient with dialysis-dependent acute kidney injury: a case against "SARS-CoV-2 Nephropathy." Kidney Int Rep. 2020;5(7):1100-5. https://doi.org/10. 1016/j.ekir.2020.05.005.

18. Sharma P, Ng JH, Bijol V, Jhaveri KD, Wanchoo R. Pathology of COVID-19-associated acute kidney injury. Clin Kidney J. 2021;14(Supplement 1):i30-9. https://doi.org/10.1093/ckj/sfab0 03.

19. Bensman A. Non-steroidal anti-inflammatory drugs (NSAIDs) systemic use: the risk of renal failure. Front Pediatr. 2020. https://doi.org/10.3389/fped.2019.00517.

20. Fontana F, Cazzato S, Giovanella S, et al. Oxalate nephropathy due to excessive vitamin $\mathrm{C}$ administration in two patients with COVID-19. Kidney Int Rep. 2020. https://doi.org/10.1016/j. ekir.2020.07.008.

21. Braun F, Edler C, Puelles VG, Huber TB. Association of SARSCoV-2 renal tropism with acute kidney injury - Authors' reply. Lancet Lond Engl. 2020;396(10266):1881-2. https://doi.org/ 10.1016/S0140-6736(20)32586-1.

22. Salute M della. Covid-19 - Situazione in Italia. http://www. salute.gov.it/portale/nuovocoronavirus. Accessed 19 June 2020.

23. WHO/COVID-19/laboratory/2020.5. Laboratory testing for 2019 novel coronavirus (2019-nCoV) in suspected human cases. https://www.who.int/publications-detail/laboratory-testing-for2019-novel-coronavirus-in-suspected-human-cases-20200117. Accessed 12 Apr 2020.

24. National Society of Infectious Diseases' (SIMIT) Guidelines for the managment of COVID-19 infection. http://www.simit.org/ 
medias/1569-covid19-vademecum-13-03-202.pdf. Accessed 5 Apr 2020.

25. Gautret P, Lagier J-C, Parola P, et al. Hydroxychloroquine and azithromycin as a treatment of COVID-19: results of an openlabel non-randomized clinical trial. Int J Antimicrob Agents. 2020. https://doi.org/10.1016/j.ijantimicag.2020.105949.

26. Yao X, Ye F, Zhang M, et al. In vitro antiviral activity and projection of optimized dosing design of hydroxychloroquine for the treatment of severe acute respiratory syndrome coronavirus 2 (SARS-CoV-2). Clin Infect Dis Off Publ Infect Dis Soc Am. 2020. https://doi.org/10.1093/cid/ciaa237.

27. Cao B, Wang Y, Wen D, et al. A trial of lopinavir-ritonavir in adults hospitalized with severe Covid-19. N Engl J Med. 2020. https://doi.org/10.1056/NEJMoa2001282.

28. Kidney Disease: Improving Global Outcomes (KDIGO) Acute Kidney Injury Workgroup. KDIGO clinical practice guideline for acute kidney injury. Kidney Int Suppl. 2012;2:1-138.

29. Levey AS, Stevens LA. Estimating GFR using the CKD Epidemiology Collaboration (CKD-EPI) creatinine equation: more accurate GFR estimates, lower CKD prevalence estimates, and better risk predictions. Am J Kidney Dis Off J Natl Kidney Found. 2010;55(4):622-7. https://doi.org/10.1053/j.ajkd.2010. 02.337 .

30. Maher RL, Hanlon JT, Hajjar ER. Clinical consequences of polypharmacy in elderly. Expert Opin Drug Saf. 2014. https:// doi.org/10.1517/14740338.2013.827660.

31. Vincent JL, Moreno R, Takala J, et al. The SOFA (Sepsisrelated Organ Failure Assessment) score to describe organ dysfunction/failure. On behalf of the Working Group on SepsisRelated Problems of the European Society of Intensive Care Medicine. Intensive Care Med. 1996;22(7):707-10. https://doi. org/10.1007/BF01709751.

32. Chertow GM, Burdick E, Honour M, Bonventre JV, Bates DW. Acute kidney injury, mortality, length of stay, and costs in hospitalized patients. J Am Soc Nephrol JASN. 2005;16(11):336570. https://doi.org/10.1681/ASN.2004090740.

33. Guan W, Ni Z, Hu Y, et al. Clinical characteristics of coronavirus disease 2019 in China. N Engl J Med. 2020;382(18):170820. https://doi.org/10.1056/NEJMoa2002032.

34. Braun F, Lütgehetmann M, Pfefferle S, et al. SARS-CoV-2 renal tropism associates with acute kidney injury. Lancet Lond Engl. 2020;396(10251):597-8. https://doi.org/10.1016/S01406736(20)31759-1.

35. Puelles VG, Lütgehetmann M, Lindenmeyer MT, et al. Multiorgan and renal tropism of SARS-CoV-2. N Engl J Med. 2020;383(6):590-2. https://doi.org/10.1056/NEJMc2011400.

36. Yu SM-W, Bonventre JV. Acute kidney injury and progression of diabetic kidney disease. Adv Chronic Kidney Dis. 2018;25(2):166-80. https://doi.org/10.1053/j.ackd.2017.12.005.

37. Hsu CY, Ordoñez JD, Chertow GM, Fan D, McCulloch CE, Go AS. The risk of acute renal failure in patients with chronic kidney disease. Kidney Int. 2008;74(1):101-7. https://doi.org/10.1038/ ki.2008.107.

38. James MT, Grams ME, Woodward M, et al. A Meta-analysis of the association of estimated gfr, albuminuria, diabetes mellitus, and hypertension with acute kidney injury. Am J Kidney Dis Off J Natl Kidney Found. 2015;66(4):602-12. https://doi.org/10.1053/j. ajkd.2015.02.338.

39. Chao C-T, Wang J, Wu H-Y, Huang J-W, Chien K-L. Age modifies the risk factor profiles for acute kidney injury among recently diagnosed type 2 diabetic patients: a population-based study. GeroScience. 2018;40(2):201-17. https://doi.org/10.1007/ s11357-018-0013-3.

40. Schiffl H. Gender differences in the susceptibility of hospitalacquired acute kidney injury: more questions than answers. Int
Urol Nephrol. 2020;52(10):1911-4. https://doi.org/10.1007/ s11255-020-02526-7.

41. Hsu RK, Hsu C. The role of acute kidney injury in chronic kidney disease. Semin Nephrol. 2016;36(4):283-92. https://doi.org/10. 1016/j.semnephrol.2016.05.005.

42. Raith EP, Udy AA, Bailey M, et al. Prognostic accuracy of the SOFA score, SIRS criteria, and qSOFA score for in-hospital mortality among adults with suspected infection admitted to the intensive care unit. JAMA. 2017;317(3):290. https://doi.org/10. 1001/jama.2016.20328.

43. Wang H, Kang X, Shi Y, et al. SOFA score is superior to APACHE-II score in predicting the prognosis of critically ill patients with acute kidney injury undergoing continuous renal replacement therapy. Ren Fail. 2020;42(1):638-45. https://doi.org/ 10.1080/0886022X.2020.1788581.

44. Teixeira C, Garzotto F, Piccinni P, et al. Fluid balance and urine volume are independent predictors of mortality in acute kidney injury. Crit Care. 2013;17(1):R14. https://doi.org/10.1186/cc124 84.

45. Hansrivijit P, Yarlagadda K, Puthenpura MM, et al. A meta-analysis of clinical predictors for renal recovery and overall mortality in acute kidney injury requiring continuous renal replacement therapy. J Crit Care. 2020;60:13-22. https://doi.org/10.1016/j.jcrc. 2020.07.012.

46. Palmieri T, Lavrentieva A, Greenhalgh DG. Acute kidney injury in critically ill burn patients. Risk factors, progression and impact on mortality. Burns. 2010;36(2):205-11. https://doi.org/10.1016/j. burns.2009.08.012.

47. Trongtrakul K, Patumanond J, Kongsayreepong S, et al. Acute kidney injury risk prediction score for critically-ill surgical patients. BMC Anesthesiol. 2020;20(1):140. https://doi.org/10. 1186/s12871-020-01046-2.

48. Bowe B, Cai M, Xie Y, Gibson AK, Maddukuri G, Al-Aly Z. Acute kidney injury in a national cohort of hospitalized US veterans with COVID-19. Clin J Am Soc Nephrol. 2021;16(1):14-25. https://doi.org/10.2215/CJN.09610620.

49. Diebold M, Schaub S, Landmann E, Steiger J, Dickenmann M. Acute kidney injury in patients with COVID-19: a retrospective cohort study from Switzerland. Swiss Med Wkly. 2021. https:// doi.org/10.4414/smw.2021.20482.

50. Fisher M, Neugarten J, Bellin E, et al. AKI in hospitalized patients with and without COVID-19: a comparison study. J Am Soc Nephrol. 2020;31(9):2145-57. https://doi.org/10.1681/ASN. 2020040509.

51. Chan L, Chaudhary K, Saha A, et al. AKI in hospitalized patients with COVID-19. J Am Soc Nephrol. 2021;32(1):151-60. https:// doi.org/10.1681/ASN.2020050615.

52. Cheng Y, Luo R, Wang X, et al. The incidence, risk factors, and prognosis of acute kidney injury in adult patients with coronavirus disease 2019. Clin J Am Soc Nephrol. 2020;15(10):1394-402. https://doi.org/10.2215/CJN.04650420.

53. Nugent J, Aklilu A, Yamamoto Y, et al. Assessment of acute kidney injury and longitudinal kidney function after hospital discharge among patients with and without COVID-19. JAMA Netw Open. 2021;4(3):e211095-e211095. https://doi.org/10. 1001/jamanetworkopen.2021.1095.

54. Alfano G, Ferrari A, Fontana F, et al. Incidence, risk factors and mortality outcome in patients with acute kidney injury in COVID19: a single-center observational study. MedRxiv. 2020. https:// doi.org/10.1101/2020.06.24.20138230.

Publisher's Note Springer Nature remains neutral with regard to jurisdictional claims in published maps and institutional affiliations. 